BMJ

Open

Gastroenterology

\section{The effects of auricular acupuncture on weight reduction and feeding-related cytokines: a pilot study}

\author{
Hisayuki Ito, ${ }^{1}$ Osamu Yamada, ${ }^{2}$ Yuji Kira, ${ }^{3}$ Takeshi Tanaka, ${ }^{4}$ Rumiko Matsuoka ${ }^{5}$
}

To cite: Ito H, Yamada 0 , Kira Y, et al. The effects of auricular acupuncture on weight reduction and feedingrelated cytokines: a pilot study. BMJ Open Gastro 2015;2: 000013 .

doi:10.1136/bmjgast-2014000013

Received 3 August 2014 Revised 3 November 2014 Accepted 23 November 2014

${ }^{1} \mathrm{KOSAI}$ Oriental Healthcare Center, Tokyo, Japan ${ }^{2}$ Faculty of Health Care, Teikyo Heisei University, Tokyo, Japan

${ }^{3}$ Showa General Hospital, Tokyo, Japan

${ }^{4}$ Department of Research Medical University, Tokyo, Japan

${ }^{5}$ Wakamatsu Kawada Clinic, Tokyo, Japan

Correspondence to Dr Osamu Yamada; yamadao@thu.ac.jp Support, Tokyo Women's

\section{ABSTRACT}

Objective: Auricular acupuncture is a common therapy used to control appetite; however, the underlying mechanism(s) of action is unclear. The present study examined changes in feeding behaviour and in the levels of several appetite-related hormones in response to auricular acupuncture, and attempted to identify the mechanism(s) by which this traditional medical treatment exerts its effects.

Methods: Ten healthy adult volunteers (nine female and one male) were recruited by the KOSAI Oriental Healthcare Center. The participants were randomly assigned to one of two groups ( $n=5$ per group): an acupuncture group and a placebo group. Each received detention needle stimulus on a weekly basis for 1 month. Changes in diet, body weight, blood pressure and blood biochemistry were evaluated before treatment and at 1 week after the start of treatment.

Results: The difference in weight before treatment and after 1 week of treatment was significant for all participants in the acupuncture group $(\mathrm{p}=0.02)$. The percentage changes in active ghrelin in the acupuncture group were no significant changes observed in active ghrelin levels at 1 week after acupuncture in any individual participant $(\mathrm{p}=0.89)$. By contrast, the percentage changes in active ghrelin levels in the placebo group at 1 week after the start of acupuncture were significant $(p=0.04)$. The insulin, adrenocorticotropic hormone, leptin and adiponectin levels did not change significantly in either group. Conclusions: There was a statistically significant difference in the percentage change in body weight and active ghrelin levels in each individual participant in auricular acupuncture groups. This is a pilot study and the sample number is small; however, auricular acupuncture may reduce appetite by suppressing ghrelin production.

\section{INTRODUCTION}

The increasing prevalence of lifestyle-associated diseases is linked to an increased incidence of arteriosclerotic conditions such as cerebral infarction and myocardial infarction, which pose a major problem from a medical and an economic point of view. Overeating is a major cause of visceral fat

\section{Summary box}

What is already known about this subject?

- Previous studies suggest that the weight reduction effect of auricular acupuncture occurs via the vagus nerve.

- However, these different experimental models have not provided definitive answers regarding treatment efficacy or the underlying mechanism of action.

- The acupuncture sites used in this study lie along the auricular branch of the vagus nerve (Arnold's nerve), which is its only somatosensory branch.

What are the new findings?

- This study examined changes in body weight and in the levels of several appetite-related peptides in response to auricular acupuncture.

- We found that the increase in early morning fasting ghrelin levels in the acupuncture group was suppressed after 1 week of auricular acupuncture treatment, whereas all of the participants in the placebo group showed an increase in early morning fasting ghrelin levels.

- Despite the small sample sizes, the results suggest that all participants in the auricular acupuncture group experienced weight loss during week 1 of the study.

How might it impact on clinical practice in the foreseeable future?

- Although this study is preliminary and the number of cases is small, it is suggested that the results provide a scientific basis for the effect of acupuncture on appetite. accumulation, and overconsumption of calories and a lack of exercise are problems for people in the busy modern world. Auricular acupuncture, a traditional form of medicine practised worldwide, can suppress the appetite, although in the West it is also used for pain relief ${ }^{1}$ and to treat drug addiction ${ }^{2}$ and anxiety. ${ }^{3}$

Appetite suppression in response to acupuncture has been studied in rats, mice and 
humans; however, these different experimental models have not provided definitive answers regarding treatment efficacy or the underlying mechanism(s) of action. ${ }^{4}$ Progress is being made in understanding the mechanisms that regulate appetite, and several appetite-regulatory peptides were recently identified. ${ }^{5}$

Previous studies suggest that the weight reduction effect of auricular acupuncture occurs via stimulation of the hunger and stomach points. ${ }^{6}$ Anatomically, the hunger point is located in the tragus, and the stomach point is located in the cuvum conchae, with both points falling within the distribution of the auricular branch of the vagus nerve. This study examined changes in feeding behaviour and in the levels of several appetite-related hormones in response to auricular acupuncture, and also attempted to identify the mechanism(s) by which this traditional medical treatment exerts its effects.

\section{MATERIALS AND METHODS}

\section{Subjects}

Ten healthy adult volunteers (nine female and one male; median age, 40 years (range, 24-44 years)) comprising students, office workers and housewives were recruited at the KOSAI Oriental Healthcare Center. The participants were randomly assigned to one of two groups $(n=5$ per group), an acupuncture group and a placebo group, using sealed envelopes. None of the participants had an endocrine disease or a history of diabetes, heart disease, allergy or immunological disease, or stroke. None were pregnant or lactating, or had given birth within the past 6 months, and all had been able to exercise to manage their weight within the past 3 months. Written consent was obtained from all participants after the study objectives, methods and safety issues were clearly and fully explained. The study protocol was approved by the Human Investigation Committee of the KOSAI Oriental Healthcare Center. All participants were free to withdraw from the study at any time.

\section{Acupuncture}

Common auricular points used for the treatment of obesity include the hunger and stomach points, which regulate satiety and fullness. ${ }^{7}$ The hunger and stomach points were located using a Chinese auriculotherapy chart $^{8}$ and Nogier's somatotopic inversion (figure 1). ${ }^{9}$ The precise locations of the acupuncture sites were identified using a Tormeter IW-ZEN device (Model 5505; Kuga Denshikiki Seisakusho, Japan), which measures autonomic nerve activity. This device detects zones of low electrical resistance in the skin; these zones correspond to acupuncture points. ${ }^{10}$ Briefly, the auriculotherapy electrode (tip diameter, $1.0 \mathrm{~mm}$ ) was used to measure electrical resistance at the hunger point in the tragus and within the distribution of the auricular branch of the vagus nerve above the auricle (where the stomach point is located). The site with the least electrical resistance was used as the acupuncture point. Auricular acupuncture

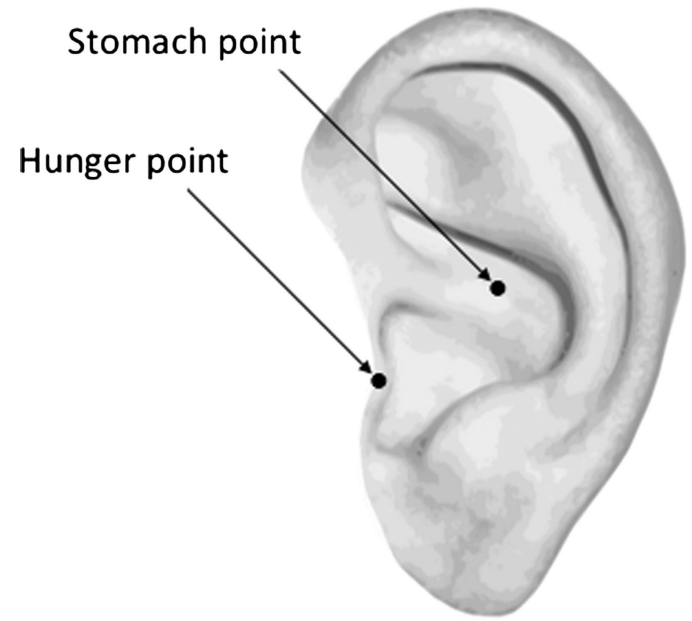

Figure 1 Acupuncture stimulation sites (hunger point and stomach point) For the acupuncture group, indwelling intradermal needles were placed at the indicated sites (arrows) and fixed in position with medical tape. For the placebo group, intradermal needles were fixed with medical tape, but did not pierce the skin.

points were selected and treatment was performed by a certified and experienced Japanese acupuncturist at the KOSAI Oriental Healthcare Center.

For the acupuncture group, the acupuncture site was cleaned with ethanol and an intradermal needle $(3 \mathrm{~mm}$ in length, $0.12 \mathrm{~mm}$ in diameter; Seirin, Japan) was inserted horizontally to a depth of approximately 1$2 \mathrm{~mm}$. Needles were inserted bilaterally. The needles were fixed with medical tape and left in position for 1 week. All needles were replaced on a weekly basis for a period of 4 weeks. A new 'session' began immediately after the needle was replaced. For the placebo group, the intradermal needle was fixed with medical tape but did not pierce the skin. Only the acupuncturist was aware of the group into which each participant had been assigned. The participants all firmly believed that they were receiving auricular acupuncture stimulation. At no point were the participants told whether or not they had received auricular acupuncture. The same acupuncture points were used for all participants, and all received acupuncture treatment once per week for four consecutive weeks (ie, four sessions) at the KOSAI Oriental Healthcare Center.

\section{Observations}

Observations were conducted on a weekly basis for four consecutive weeks. Body weight, waist circumference and body mass index (BMI) were recorded before the start of the study and then on a weekly basis thereafter. Both groups kept a record of their diet during the study and a dietician assessed the food intake of each participant from pictures taken with a digital camera. No subjective measures were performed; however, changes in diet and food intake were monitored through the dietician's records. Both groups were instructed to carry on as normal during the observation period, although they 
were not allowed to receive acupuncture or to take any medications.

\section{Urinalysis and blood tests}

Fasting urine and blood samples were collected by a medical doctor at Tokyo Women's Medical University before the study began and again after 1 week of acupuncture treatment (before the needle was replaced). Samples were collected early in the morning before breakfast (between 6:30 and 8:00). A new acupuncture session began after the blood sample was collected.

In addition to general urinalysis, blood biochemistry and haematological tests were performed and the concentrations of insulin, C-peptide, leptin, adiponectin, adrenocorticotropic hormone (ACTH), active ghrelin and desacyl-ghrelin were measured. Blood ghrelin concentrations were measured using active ghrelin ELISA and desacyl-ghrelin ELISA kits (SCETI, Japan). All tests were performed by Mitsubishi Chemical Medience (Japan). The percentage changes in the levels of appetite-regulating factors were calculated as follows: ((value after acupuncture-value before acupuncture)/ value before acupuncture $\times 100$, where before acupuncture: before the study began, and after acupuncture: after 1 week and immediately before a new session began.

\section{Statistical analysis}

SAS software (V.9.1; SAS Institute, USA) was used for all statistical analyses. A paired t test was used to compare changes in body weight and changes in the levels of appetite-regulatory peptides both before the study and at 1 week after the start of acupuncture. A $p$ value $<0.05$ was considered significant.

\section{RESULTS}

\section{Participant characteristics and general test results}

The median age of the participants in the acupuncture group (participants A-E) was 43 years (range, 40-44 years) and that of the participants in the placebo group (participants $\mathrm{F}-\mathrm{J}$ ) was 35 years (range, 24-43 years). The acupuncture group comprised four women and one man, and the placebo group comprised five women. The median body weight in the acupuncture group was $62.4 \mathrm{~kg}$ (range, 55.8-94.7 kg) and that in the placebo group was $60.2 \mathrm{~kg}$ (range, 53-82 kg; table 1). No abnormal haematology, blood biochemistry or lipid results were recorded for either group.

\section{Changes in body weight}

Figure 2 shows body weight before the study and after 1 week of treatment for all participants in the acupuncture group. Participant A lost $2.6 \mathrm{~kg}$, which was the largest percentage change $(-3.5 \%)$. The percentage changes in body weight for participants $\mathrm{B}, \mathrm{C}, \mathrm{D}$, and $\mathrm{E}$ were $-0.7 \%,-2.6 \%,-3 \%$, and $-1 \%$, respectively. The difference in weight before treatment and after 1 week of treatment was significant for all participants in the acupuncture group $(\mathrm{p}=0.02)$.

The percentage changes in body weight for participants in the placebo group over the same period were $+1.3 \%$ (participant $\mathrm{F}$ ), $+0.3 \%$ (participant I) and $0 \%$ (participants $\mathrm{G}, \mathrm{H}$, and $\mathrm{J}$ ). These changes were not significant $(p=0.18)$.

\section{Changes in appetite-regulatory peptide levels}

Tables 2 and 3 show the levels of biochemistry and appetite-regulatory peptides before treatment and at 1 week after the start of treatment. There were no clear differences in the fasting blood sugar, insulin, ACTH, adiponectin or leptin levels between the two groups. Figure 3 shows the percentage changes in active ghrelin levels 1 week after the start of acupuncture (with respect to baseline levels). The percentage changes in active ghrelin in the acupuncture group were $-28 \%$ (participant A), $+11 \%$ (participant $\mathrm{B}$ ), $+20 \%$ (participant $\mathrm{C}$ ), $-19 \%$ (participant $\mathrm{D}$ ) and $+2 \%$ (participant $\mathrm{E}$ ), with no significant changes observed in active ghrelin levels at 1 week after acupuncture in any individual participant

\begin{tabular}{|c|c|c|c|c|c|c|c|c|}
\hline Case & Age & Sex & $\begin{array}{l}\text { Height } \\
\text { (cm) }\end{array}$ & $\begin{array}{l}\text { Weight } \\
\text { (kg) }\end{array}$ & BMI & $\begin{array}{l}\text { Waist circumference } \\
\text { (cm) }\end{array}$ & $\begin{array}{l}\text { Blood pressure } \\
(\mathrm{mm} \mathrm{Hg})\end{array}$ & $\begin{array}{l}\text { Heart rate } \\
(\mathrm{bpm})\end{array}$ \\
\hline \multicolumn{9}{|c|}{ Acupuncture group } \\
\hline A & 44 & $\mathrm{~F}$ & 169 & 74.9 & 26.3 & 85 & $112 / 90$ & 61 \\
\hline B & 44 & $\mathrm{~F}$ & 156 & 55.8 & 23 & 75.1 & $120 / 73$ & 67 \\
\hline $\mathrm{C}$ & 43 & $\mathrm{~F}$ & 156 & 58.3 & 23.8 & 82 & $101 / 72$ & 62 \\
\hline D & 40 & $\mathrm{~F}$ & 159 & 62.4 & 24.5 & 80.3 & $116 / 80$ & 72 \\
\hline E & 40 & $M$ & 173 & 94.7 & 31.7 & 106.2 & $136 / 95$ & 72 \\
\hline \multicolumn{9}{|c|}{ Placebo group } \\
\hline $\mathrm{F}$ & 24 & $\mathrm{~F}$ & 172.5 & 60.2 & 20.3 & 79 & $113 / 81$ & 72 \\
\hline G & 34 & $\mathrm{~F}$ & 161 & 54.4 & 20.8 & 68.2 & $110 / 73$ & 84 \\
\hline $\mathrm{H}$ & 43 & $\mathrm{~F}$ & 159 & 53 & 21 & 76.1 & $95 / 57$ & 66 \\
\hline I & 43 & $\mathrm{~F}$ & 157.8 & 65.2 & 26.4 & 86.2 & $117 / 71$ & 85 \\
\hline $\mathrm{J}$ & 35 & $\mathrm{~F}$ & 170 & 82 & 28.4 & 97 & $117 / 59$ & 76 \\
\hline
\end{tabular}




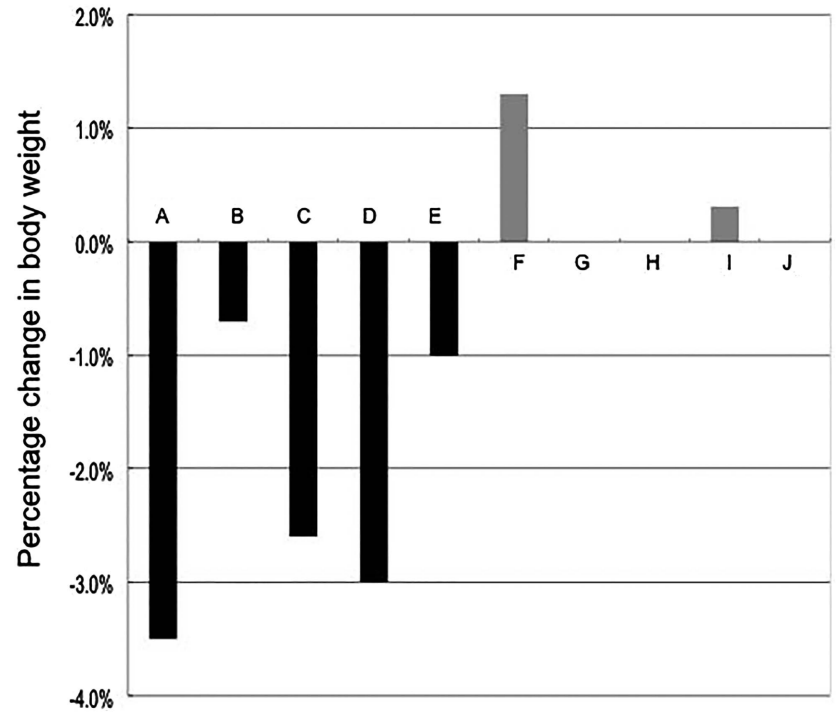

Figure 2 Percentage change in body weight at 1 week after the start of acupuncture treatment. Black columns denote the acupuncture group (A-E) and grey columns denote the placebo group $(\mathrm{F}-\mathrm{J})$. The percentage change in body weight was calculated as follows: ((value after stimulation-value before stimulation)/value before stimulation) $\times 100$ (\%). A significant reduction in body weight was observed for all members of the acupuncture group $(p=0.02)$.

$(\mathrm{p}=0.89)$. In contrast, the percentage changes in active ghrelin levels in the placebo group at 1 week after the start of acupuncture were $+434 \%$ (participant $\mathrm{F}$ ), $+14 \%$ (participant G), $+149 \%$ (participant $\mathrm{H}$ ), $+64 \%$ (participant I) and $+29 \%$ (participant J); all of these were significant $(\mathrm{p}=0.04)$. The leptin and adiponectin levels did not change significantly in either group. The dietician assessed reductions in food intake by estimating the nutritional value of each meal from photographs.

\section{Adverse effects}

No major adverse effects were observed during the study, and none of the participants withdrew from the study due to discomfort associated with the treatment.

\section{DISCUSSION}

Auricular acupuncture therapy has been practised in China since ancient times; however, it has become internationally recognised due to the work of the French physician Paul Nogier. ${ }^{11}$ Acupuncture is widely used to treat many symptoms/conditions, and auricular acupuncture is the method most often used to treat obesity. ${ }^{12}$

The objective of this study was to identify the mechanism(s) by which auricular acupuncture therapy suppresses appetite in humans. To this end, we enrolled 10 volunteers: 5 had an indwelling intradermal needle inserted in the auricle and 5 had the needle taped to the auricle but not inserted. Body weight and the levels of several appetite-regulatory peptides were measured to examine treatment effects. Despite the small sample sizes, the results suggest that all participants in the auricular acupuncture group experienced weight loss during week 1 of the study. However, the sample was heterogeneous with respect to BMI. Therefore, future studies should examine the influence of acupuncture in groups of individuals of different body weight (ie, normal, overweight and obese individuals).

The mechanism(s) underlying the weight loss observed after auricular acupuncture remains unclear, although the vagus nerve is thought to be involved. ${ }^{13}$ The acupuncture sites used in this study lie along the auricular branch of the vagus nerve (Arnold's nerve), which is its only somatosensory branch. Animal studies investigating the relationship between acupuncture and gastric peristalsis and feeding have been conducted. ${ }^{14}$ For example, Shiraishi et al investigated the effects of auricular acupuncture on neuronal activity in the feeding centre (lateral hypothalamic area: LHA) in a rat model of simple obesity, and on neuronal activity in the satiety centre (ventromedial nucleus of the hypothalamus: HVM) in a rat model of hypothalamic obesity (in which the satiety centre was disrupted). Using electrophysiological techniques, they found that auricular acupuncture stimulates the LHA via the auricular branch of the vagus nerve and inhibits the excitability of LHA neurons. They also reported evidence of signal transduction between the auricle and the hypothalamus, and noted that auricular acupuncture increased the activity of HVM neurons, thereby contributing to the induction or maintenance of satiety. ${ }^{15}$ In addition, Asamoto et $a l^{16}$ reported that auricular acupuncture increased HVM neuronal activity in rats, which led to a reduction in body weight. Therefore, auricular acupuncture may also suppress LHA neuronal activity via an afferent pathway of the vagus nerve and activate HVM neuronal activity in humans, which may lead to decreased food intake and subsequent weight loss.

In humans, the effects of auricular acupuncture often manifest as changes in body weight ${ }^{17}$ and subcutaneous fat levels, ${ }^{18}$ as assessed by modalities such as CT scan. In this study, we also measured the levels of appetiteregulatory peptides. We found that the increase in early morning fasting ghrelin levels in the acupuncture group was suppressed after 1 week of acupuncture, whereas all of the participants in the placebo group showed an increase in early morning fasting ghrelin levels. The serum ghrelin level change is affected by blood glucose and insulin levels. ${ }^{19}$ The changes in blood glucose and insulin levels were not significantly different between the acupuncture and placebo groups. The mechanism underlying this phenomenon may involve the interaction between feeding-related cytokines and the vagus nerve. Since the vagus nerve controls peristalsis, its nerve endings are distributed throughout the mucosa and submucosa of the gastrointestinal tract. The nerve also transmits neurochemical signals (triggered by gastrointestinal hormones) to the diencephalon and neocortex via the brainstem. Ghrelin is the only 


\begin{tabular}{|c|c|c|c|c|c|c|c|c|c|c|c|c|c|c|c|c|}
\hline Case & Measurement time & $\begin{array}{l}\text { WCC } \\
(/ \mu L)\end{array}$ & $\begin{array}{l}\text { RBC } \\
\left(\times 10^{4} / \mu \mathrm{L}\right)\end{array}$ & $\begin{array}{l}\text { Hb } \\
\text { (g/dL) }\end{array}$ & $\begin{array}{l}\mathrm{Ht} \\
(\%)\end{array}$ & $\begin{array}{l}\text { MCV } \\
\text { (fL) }\end{array}$ & $\begin{array}{l}\mathrm{MCH} \\
(\mathrm{pg})\end{array}$ & $\begin{array}{l}\text { MCHC } \\
(\%)\end{array}$ & $\begin{array}{l}\text { Platelet } \\
(\mu \mathrm{L})\end{array}$ & $\begin{array}{l}\text { AST } \\
\text { (IU/L) }\end{array}$ & $\begin{array}{l}\text { ALT } \\
\text { (IU/L) }\end{array}$ & $\begin{array}{l}T P \\
\text { (g/dL) }\end{array}$ & $\begin{array}{l}\text { BUN } \\
\text { (mg/dL) }\end{array}$ & $\begin{array}{l}\text { HDL } \\
\text { (mg/dL) }\end{array}$ & $\begin{array}{l}\text { LDL } \\
\text { (mg/dL) }\end{array}$ & $\begin{array}{l}\text { FBS } \\
\text { (mg/dL) }\end{array}$ \\
\hline \multicolumn{17}{|c|}{ Acupuncture group } \\
\hline \multirow[t]{2}{*}{ A } & Before & 4800 & 387 & 11.4 & 35.9 & 93 & 29.5 & 31.8 & 22.3 & 14 & 12 & 7.7 & 18.1 & 51 & 125 & 98 \\
\hline & 1 week & 4200 & 406 & 11.8 & 36.7 & 90 & 29.1 & 32.2 & 19.7 & 19 & 28 & 7.8 & 14.8 & 49 & 112 & 99 \\
\hline \multirow[t]{2}{*}{$\mathrm{B}$} & Before & 5400 & 449 & 13.6 & 42.2 & 94 & 30.3 & 32.2 & 18 & 27 & 31 & 6.4 & 13.6 & 55 & 34 & 92 \\
\hline & 1 week & 4800 & 441 & 13.2 & 41.3 & 94 & 29.9 & 32 & 17 & 23 & 28 & 6.6 & 14.3 & 61 & 36 & 93 \\
\hline \multirow[t]{2}{*}{$\mathrm{C}$} & Before & 5300 & 411 & 11.5 & 38.3 & 93 & 28 & 30 & 37.2 & 21 & 9 & 7.6 & 13.1 & 71 & 115 & 96 \\
\hline & 1 week & 5400 & 427 & 11.9 & 38.7 & 91 & 27.9 & 30.7 & 35.3 & 20 & 10 & 7.7 & 11.9 & 68 & 118 & 96 \\
\hline \multirow[t]{2}{*}{$\mathrm{D}$} & Before & 3200 & 428 & 13.2 & 41.4 & 97 & 30.8 & 31.9 & 22 & 22 & 18 & 7.1 & 12.2 & 51 & 94 & 81 \\
\hline & 1 week & 3600 & 425 & 13.2 & 41.1 & 97 & 31.1 & 32.1 & 20.6 & 20 & 16 & 7 & 11.2 & 55 & 94 & 84 \\
\hline \multirow[t]{2}{*}{$E$} & Before & 8300 & 488 & 14.7 & 45 & 92 & 30.1 & 32.7 & 28.7 & 25 & 32 & 7.7 & 9.5 & 62 & 118 & 98 \\
\hline & 1 week & 7700 & 489 & 14.7 & 45.2 & 92 & 30.1 & 32.5 & 27.4 & 26 & 41 & 7.5 & 8.7 & 52 & 120 & 104 \\
\hline \multicolumn{17}{|c|}{ Placebo group } \\
\hline \multirow[t]{2}{*}{$\mathrm{F}$} & Before & 4700 & 453 & 12.6 & 40.1 & 89 & 27.8 & 31.4 & 22.3 & 23 & 20 & 7.7 & 10.5 & 48 & 100 & 83 \\
\hline & 1 week & 5600 & 469 & 13 & 41.5 & 88 & 27.7 & 31.3 & 20 & 18 & 15 & 7.8 & 11.5 & 55 & 107 & 85 \\
\hline \multirow[t]{2}{*}{$G$} & Before & 5200 & 457 & 13.7 & 44.3 & 97 & 30 & 30.9 & 17.9 & 21 & 20 & 7.4 & 17.5 & 67 & 79 & 76 \\
\hline & 1 week & 4400 & 458 & 13.7 & 44.2 & 97 & 29.9 & 31 & 16.9 & 19 & 21 & 7.6 & 12.8 & 71 & 75 & 80 \\
\hline \multirow[t]{2}{*}{$\mathrm{H}$} & Before & 5700 & 448 & 13.6 & 42 & 94 & 30.4 & 32.4 & 20.8 & ND & ND & ND & ND & ND & ND & 89 \\
\hline & 1 week & 5000 & 443 & 13.4 & 42.5 & 96 & 30.2 & 31.5 & 23.3 & 19 & 13 & 7.3 & 11 & 89 & 118 & 88 \\
\hline \multirow[t]{2}{*}{ I } & Before & 6600 & 436 & 8.8 & 31.7 & 73 & 20.2 & 27.8 & 46.4 & 13 & 15 & 7.6 & 13.1 & 46 & 146 & 90 \\
\hline & 1 week & 6300 & 423 & 8.3 & 29.9 & 71 & 19.6 & 27.8 & 56 & 15 & 17 & 7.8 & 13.4 & 46 & 121 & 94 \\
\hline \multirow[t]{2}{*}{ J } & Before & 4500 & 455 & 13.9 & 41.6 & 91 & 30.5 & 33.4 & 18.5 & 17 & 12 & 7.3 & 13.9 & 43 & 130 & ND \\
\hline & 1 week & 4900 & 433 & 13.6 & 40.2 & 93 & 31.4 & 33.8 & 19.3 & 15 & 13 & 7.1 & 11.7 & 45 & 124 & 88 \\
\hline
\end{tabular}

ALT, alanine transaminase; AST, aspartate transaminase; BUN, Blood urea nitrogen; FBS, fasting blood sugar; Hb, haemoglobin; HDL, high-density lipoprotein; Ht, haematocrit; LDL, low-density lipoprotein; $\mathrm{MCH}$, mean corpuscular haemoglobin; $\mathrm{MCHC}, \mathrm{MCH}$ concentration; MCV, mean corpuscular volume; ND, not done because of insufficient blood samples; RBC, red blood cell; TP, total protein; WCC, white cell count. 
Table 3 Changes in feeding-related peptides

\begin{tabular}{|c|c|c|c|c|c|c|c|c|}
\hline Case & Measurement time & $\begin{array}{l}\text { Insulin } \\
(\mu \mathrm{U} / \mathrm{mL})\end{array}$ & $\begin{array}{l}\text { C-peptide } \\
\text { (ng/mL) }\end{array}$ & $\begin{array}{l}\text { ACTH } \\
(\mathrm{pg} / \mathrm{mL})\end{array}$ & $\begin{array}{l}\text { Leptin } \\
\text { (ng/mL) }\end{array}$ & $\begin{array}{l}\text { Active ghrelin } \\
\text { (fmol/mL) }\end{array}$ & $\begin{array}{l}\text { Desacyl-ghrelin } \\
\text { (fmol/mL) }\end{array}$ & $\begin{array}{l}\text { Adiponectin } \\
(\mu \mathrm{g} / \mathrm{mL})\end{array}$ \\
\hline \multicolumn{9}{|c|}{ Acupuncture group } \\
\hline \multirow[t]{2}{*}{ A } & Before & 5.9 & 1.1 & 13 & 13.2 & 4.65 & 83.8 & 8.57 \\
\hline & 1 week & 5.1 & 1 & 12 & 9.8 & 3.36 & 40.4 & 7.33 \\
\hline \multirow[t]{2}{*}{ B } & Before & 2.8 & 1 & 22 & 8 & 15.3 & 172 & 5.08 \\
\hline & 1 week & 5.4 & 1.4 & 18 & 8.7 & 17.1 & 174 & 5.15 \\
\hline \multirow[t]{2}{*}{ C } & Before & 3.6 & 1 & 13 & 5.9 & 20.7 & 206 & 7.64 \\
\hline & 1 week & 6.8 & 1.4 & 21 & 6.3 & 24.9 & 164 & 6.59 \\
\hline \multirow[t]{2}{*}{$\mathrm{D}$} & Before & 9.5 & 2.5 & 27 & 11.2 & 3.36 & 77.2 & 4.2 \\
\hline & 1 week & 10.6 & 2.2 & 25 & 10.6 & 3.42 & 46.6 & 4.51 \\
\hline \multirow[t]{2}{*}{$E$} & Before & 3 & 1.2 & 42 & 11.5 & 27.9 & ND & 13.6 \\
\hline & 1 week & 3.7 & 1.3 & 47 & 12 & 22.5 & 387 & 11.4 \\
\hline \multicolumn{9}{|c|}{ Placebo group } \\
\hline \multirow[t]{2}{*}{$\mathrm{F}$} & Before & 6.8 & 2.7 & 17 & 11.8 & 6.14 & 175 & 8.56 \\
\hline & 1 week & 14.5 & 2.4 & 23 & 12.9 & 32.8 & 114 & 6.83 \\
\hline \multirow[t]{2}{*}{$\mathrm{G}$} & Before & 4.2 & 0.8 & 41 & 5.4 & 15.2 & 93 & 7.74 \\
\hline & 1 week & 3.8 & 1.1 & 24 & 5 & 17.3 & 102 & 8.99 \\
\hline \multirow[t]{2}{*}{$\mathrm{H}$} & Before & ND & ND & 15 & 11.6 & 11.3 & 314 & 11.4 \\
\hline & 1 week & 6.9 & 1.2 & 18 & 10.5 & 28.1 & 138 & 10.3 \\
\hline \multirow[t]{2}{*}{1} & Before & 6.2 & 1.3 & 34 & 10.2 & 11 & 208 & 8.36 \\
\hline & 1 week & 11.1 & 2 & 31 & 11.5 & 18 & 102 & 8.47 \\
\hline \multirow[t]{2}{*}{$\mathrm{J}$} & Before & 5.8 & 1.2 & 19 & 10.5 & 5.95 & 43.4 & 2.33 \\
\hline & 1 week & 6.5 & 1.5 & 18 & 14.7 & 7.63 & 170 & 2.51 \\
\hline
\end{tabular}

appetite-inducing peptide produced peripherally; ${ }^{20}$ the hormone is produced primarily by gastrointestinal endocrine cells located within the gastric body and it plays an important role in energy metabolism by increasing appetite and regulating gastrointestinal functions. Ghrelin transmits information about hunger and growth hormone levels to the nerve centre via afferent vagal

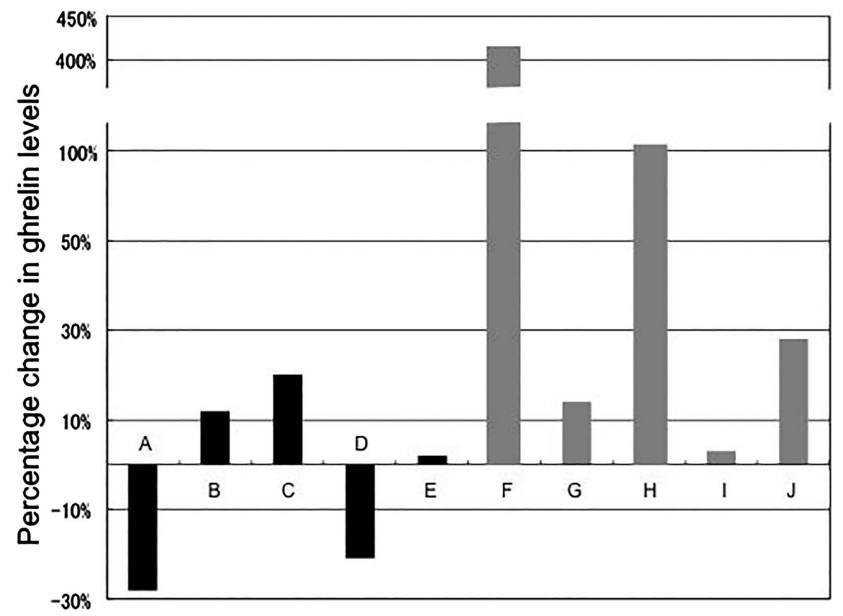

Figure 3 Percentage change in ghrelin levels at 1 week after the start of acupuncture. Black columns denote the acupuncture group (A-E) and grey columns denote the placebo group $(\mathrm{F}-\mathrm{J})$. The percentage change in ghrelin levels was calculated as follows: ((value after stimulation-value before stimulation)/value before stimulation) $\times 100(\%)$. No member of the acupuncture group showed a significant increase in active ghrelin levels $(p=0.89)$. pathways and through the blood. ${ }^{21}$ The concentration of ghrelin in the blood rises during fasting and decreases after eating. Ghrelin can pass through the blood-brain barrier and bind to ghrelin receptors in the arcuate nucleus of the hypothalamus. ${ }^{22}$ However, ghrelin receptors are also expressed at the vagal afferent terminals, ${ }^{23}$ and ghrelin excreted from the stomach transmits signals to the nerve centre via these receptors, which increases the appetite. ${ }^{24}$ Ghrelin is secreted when the stomach is empty, which promotes gastric peristalsis. The hormone then stimulates the brain via the circulation (it is present in the blood) and via vagal afferent pathways. Electrical signals are then transmitted to the stomach via vagal efferent pathways, which again induce gastric peristalsis.

Hsu et $a t^{55}$ conducted a randomised controlled trial of auricular acupuncture in 45 obese women. The acupuncture sites were the same as those used in this study and the results confirmed the biochemical effects of auricular acupuncture in humans. However, there was no clear difference between the acupuncture and placebo groups in terms of body weight before and after treatment. Furthermore, significant decreases in leptin levels and significant increases in ghrelin levels were observed in the acupuncture group. These results are different from those reported in this study. This difference may be attributable to the fact that we compared percentage changes in body weight and ghrelin levels in each individual participant before as well as after treatment, whereas Hsu et al compared the group values. Also, with regard to changes in body weight, Hsu et al compared values after 6 weeks and found no differences, whereas this study found that body 
weight decreased in the acupuncture group after 1 week of treatment; however, in three of the five participants, body weight returned to pretreatment levels after 4 weeks of treatment (which appeared to correspond with an increase in calorie intake after week 1). Therefore, it may be that the use of an indwelling needle led to an increase in the threshold level for acupuncture stimulation, leading to a reduction in the effect over time. In future, it may be necessary to conduct human studies using electroacupuncture therapy, as used in rats. ${ }^{26}$

\section{CONCLUSION}

The difference in weight before treatment and after 1 week of treatment was significant for all participants in the acupuncture group $(\mathrm{p}=0.02)$. The percentage changes in body weight in the placebo group were not significant $(\mathrm{p}=0.18)$.

The percentage changes in active ghrelin in the acupuncture group were no significant changes observed in active ghrelin levels at 1 week after acupuncture in any individual participant $(\mathrm{p}=0.89)$, whereas all of the participants in the placebo group showed an increase in early morning fasting ghrelin levels $(p=0.04)$. Thus, the sample number is small, but auricular acupuncture may reduce appetite by suppressing ghrelin production.

Acknowledgements The authors are grateful to the volunteers who participated in this study. They would also like to thank Yoshiko Fukushima, registered dietician, for analysing the content of the diets.

Contributors $\mathrm{HI}$ and $\mathrm{OY}$ designed the study, were responsible for the study concept and design and were involved in assessment, data entry and checking, statistical analysis and drafting of the manuscript. OY and TT extracted and analysed the data. OY offered support and advice at all stages of the study, and assisted with the revision of the manuscript.

Competing interests None.

Patient consent Obtained.

Ethics approval The study protocol was approved by the Human Investigation Committee of the KOSAI Oriental Healthcare Center.

Provenance and peer review Not commissioned; externally peer reviewed.

Data sharing statement The original data of this study can be accessed through OY via email.

Open Access This is an Open Access article distributed in accordance with the Creative Commons Attribution Non Commercial (CC BY-NC 4.0) license, which permits others to distribute, remix, adapt, build upon this work noncommercially, and license their derivative works on different terms, provided the original work is properly cited and the use is non-commercial. See: http:// creativecommons.org/licenses/by-nc/4.0/

\section{REFERENCES}

1. Bernateck M, Becker M, Schwake C, et al. Adjuvant auricular electroacupuncture and autogenic training in rheumatoid arthritis: a randomized controlled trial. Auricular acupuncture and autogenic training in rheumatoid arthritis. Forsch Komplementmed 2008;15:187-93.

2. Avants SK, Margolin A, Holford TR, et al. A randomized controlled trial of auricular acupuncture for cocaine dependence. Arch Intern Med 2000;160:2305-12.

3. Courbasson CM, de Sorkin AA, Dullerud B, et al. Acupuncture treatment for women with concurrent substance use and anxiety/ depression: an effective alternative therapy? Fam Community Health 2007;30:112-20.

4. Cabioglu MT, Ergene N, Surucu HS, et al. Serum, IgG, IgA, IgM, and IgE levels after electroacupuncture and diet therapy in obese women. Am J Chin Med 2007;35:955-65.

5. Inui A, Asakawa A, Bowers CY, et al. Ghrelin, appetite, and gastric motility: the emerging role of the stomach as an endocrine organ. FASEB J 2004; 18:439-56.

6. Lacey JM, Tershakovec AM, Foster GD. Acupuncture for the treatment of obesity: a review of the evidence. Int J Obes Relat Metab Disord 2003;27:419-27.

7. Huang MH, Yang RC, Hu SH. Preliminary results of triple therapy for obesity. Int J Obes Relat Metab Disord 1996;20:830-6.

8. Stux G, Pomeranz B. Acupuncture: textbook and atlas. Berlin: Springer-Verlag, 1987:30.

9. Nogier P, Bourdiol R, Corcelle A. Auriculotherapy. Chir Dent Fr 1976;46:61-3.

10. Usichenko TI, Lysenjuk VP, Groth M, et al. Detection of ear acupuncture points by measuring the electrical skin resistance in patients before, during and after orthopedic surgery performed under general anesthesia. Acupunct Electrother Res 2003;28:167-73.

11. Gori L, Firenzuoli F. Ear acupuncture in European traditional medicine. Evid Based Complement Alternat Med 2007;4(Suppl 1):13-16.

12. Mok MS, Parker LN, Voina S, et al. Treatment of obesity by acupuncture. Am J Clin Nutr 1976;29:832-5.

13. Choy DS, Eidenschenk E. Effect of tragus clips on gastric peristalsis: a pilot study. J Altern Complement Med 1998;4:399-403.

14. Ishibashi S. The effect of auricular electroacupuncture on the neuronal activity of the thalamic and hypothalamic neurons of the rat. Acupunct Electrother Res 1986;11:15-23.

15. Shiraishi T, Onoe M, Kojima T, et al. Effects of auricular stimulation on feeding-related hypothalamic neuronal activity in normal and obese rats. Brain Res Bull 1995;36:141-8.

16. Asamoto $\mathrm{S}$, Takeshige $\mathrm{C}$. Activation of the satiety center by auricular acupuncture point stimulation. Brain Res Bull 1992:29:157-64.

17. Allison DB, Kreibich $\mathrm{K}$, Heshka S, et al. A randomised placebo-controlled clinical trial of an acupressure device for weight loss. Int J Obes Relat Metab Disord 1995;19:653-8.

18. Shiraishi T, Onoe M, Kageyama T, et al. Effects of auricular acupuncture stimulation on nonobese, healthy volunteer subjects. Obes Res 1995;5:667-73.

19. Barazzoni R. Ghrelin and insulin secretion in humans: not a tale of two hormones? Diabetes 2014;63:2213-15.

20. Kojima M, Hosoda H, Date Y, et al. Ghrelin is a growth-hormone-releasing acylated peptide from stomach. Nature 1999:402:656-60.

21. Date $\mathrm{Y}, \mathrm{Kojima} \mathrm{M}, \mathrm{Hosoda} \mathrm{H}$, et al. Ghrelin, a novel growth hormone-releasing acylated peptide, is synthesized in a distinct endocrine cell type in the gastrointestinal tracts of rats and humans. Endocrinology 2000;141:4255-61.

22. Nakazato M, Murakami N, Date $\mathrm{Y}$, et al. A role for ghrelin in the central regulation of feeding. Nature 2001;409:194-8.

23. Date $\mathrm{Y}$, Murakami $\mathrm{N}$, Toshinai $\mathrm{K}$, et al. The role of the gastric afferent vagal nerve in ghrelin-induced feeding and growth hormone secretion in rats. Gastroenterology 2002;123:1120-8.

24. McKee KK, Palyha OC, Feighner SD, et al. Molecular analysis of rat pituitary and hypothalamic growth hormone secretagogue receptors. Mol Endocrinol 1997;11:415-23.

25. Hsu CH, Wang CJ, Hwang KC, et al. The effect of auricular acupuncture in obese women: a randomized controlled trial. $J$ Womens Health (Larchmt) 2009;18:813-18.

26. Tian N, Wang F, Tian DR, et al. Electroacupuncture suppresses expression of gastric ghrelin and hypothalamic NPY in chronic food restricted rats. Peptides 2006;27:2313-20. 